\title{
The balance between governance support needed and influence avoided: The case of population censuses
}

\author{
Jean-Michel Durr \\ National Institute of Statistics and Economic Studies (Insee), France \\ E-mail: jean-michel.durr@insee.fr
}

\begin{abstract}
Population and housing censuses are large operations mobilizing the whole country. The National Statistical Office, usually in charge of the preparation and implementation of the census, does not have the permanent resources to conduct it on its own and needs support from the national government as well as from local authorities. There are three areas where the government plays a role in a census. It provides the legal framework to conduct the census; funding for the census; and logistical support. Local authorities provide also logistical support and, in some countries, a 'democratic control' of the fairness of the enumeration operations. However, the involvement of national and local authorities in the census operations is not without pitfalls. The independence of the census may be jeopardized, and the census perceived by the population as an administrative operation rather than a statistical one. This may entail lack of trust from the population on the use of the data and the confidentiality guaranteed to the information provided. Based on examples in the Western Balkans, Asia and Africa, the paper discusses the optimal balance between governance support and influence avoided in the population and housing census operations.
\end{abstract}

Keywords: Population and housing census, quality, governance

\section{Introduction}

According to the Fundamental Principles of Official statistics [1], the statistical agencies need to decide according to strictly professional considerations, including scientific principles and professional ethics, on the methods and procedures for the collection, processing, storage and presentation of statistical data. However, population and housing censuses are large operations that usually cannot be conducted solely by the National Statistical Office without support of the Government. According the UN, there are three areas where the Government plays a role in a census [2].

Firstly, the Government provides the legal framework to conduct the census. A comprehensive framework, entrusting the census agency to carry out census activities, providing for the role of government departments in the operation, and including provisions related to the obligations of the participants as well as confidentiality safeguard measures is needed to conduct the census in a proper way.

Secondly, Government provides funding for the census, at least partially. Agreement by Government on the level of funding for the census is needed early in the cycle, from preparation to data collection and processing, so that other aspects of census planning can proceed.

Thirdly, the Government provides logistical support to the census. For example, in some countries, teachers are mobilized as enumerators, with the support of the Ministry of Education. Ministry of Justice provides access to the prisons for the enumeration of prisoners. Other government agencies sometimes supply specialist services such as form printing, mapping, transport services or media liaison. At local level, local authorities are called upon to provide training rooms and equipment, and meeting space for field staff.

In this context, the population and housing census can be considered as an administrative operation, under 
the control of the Government, rather than as strictly statistical operation. The perception of a census as a largely administrative operation could lead to reluctance of the population to participate in a governmental operation, people not trusting the neutrality of the operation and the confidentiality of their responses.

\section{Government or political interference in census operations}

However, it may happen that the government goes beyond its supporting role as defined above and attempts to interfere in the technical organisation and conduct of the census. Political leaders may also tend to interfere with census operations in relation with their political agenda.

Interference can be defined as actions to prevent a process or activity from continuing or being carried out properly. Objectives may be to influence the results of the census, for example in terms of size of the population at national or sub-national level, or in terms of the relative weight of population groups (religious or ethnic groups, for example) or seize opportunity of the census to highlight its achievements.

Government or political interference, as defined above, can take various forms: introduction or removal of specific questions; exclusion of specific population groups or inclusion of non-resident groups; alteration of the results during the processing phase; delays or non-dissemination of the results. Several steps of census operations can thus be affected. Based on observations or in documentation provided by international monitoring operations, we will give examples of such cases in the various phases of the census operation.

\subsection{Questionnaire design}

Whereas it is normal for the Government to express its needs for topics to be included in the questionnaire for considerations of policy making, it can happen that the Government or political leaders try to interfere with the census operation by influencing the content of the questionnaire. In some countries the census questionnaire is submitted for approval to the Government, leading to possible interference as in Canada when the Government decided to abolish the obligation to answer to the long form of the census 2011.

Despite the risk to jeopardize the census due to the sensitivity of the ethnicity topic, Western Balkans countries governments pushed to include such topic, as well as religion and mother tongue, in the census questionnaire. The most illustrative example is North Macedonia, where the distribution of ethnic groups has a direct impact on the civil rights of the population groups in application of the Orhid agreement. Despite warnings that asking for ethnic affiliation in the 2011 census questionnaire would lead to inevitable tensions among communities and frauds, the Government maintained its request to include these sensitive questions in the census. The disorders and ethnic tensions that these sensitive questions triggered during the fieldwork forced to stop the operation after ten days into the enumeration period. Nevertheless, it seems that the next 2020 census will still include these questions. This example reveals the naive belief that a statistical operation can collect any information, regardless its sensitivity, which is of course false. The paradigm governing statistical activities is that respondents have no interest in lying or in tampering with their answers, but if their response may have a direct consequence on their civil rights, it is likely to generate frauds.

In Bosnia and Herzegovina, the formulation of a question on the ethnic affiliation raised issues. International monitoring observers advised to stick to an open-ended question, as recommended internationally, to allow individuals to answer such questions freely, while political pressure pushed to ask the question using predefined boxes proposing the three ethnicities "constituents" of the population according to the constitution, and an option "other, specify". A compromise was reached, but this was not in full compliance with international recommendations.

More recently, the request of the US Government to include a question on citizenship in the census 2020 raised concern about the risk that undocumented migrants might decline to respond to the census. By law, the Census Bureau, part of the Department of Commerce, is not allowed to share individuals' data with law enforcement agencies, but some immigrants may nevertheless have that fear. Because census data is used to apportion seats in the US House of Representatives, dole out federal funding and serve as the basis for statelevel political districts, an undercount of immigrants could affect a state or city's political representation for a decade. The case came to the Supreme Court who rejected the commerce department's stated justification for including a question on citizenship.

\subsection{Field work}

Instructions given by the Government during fieldwork sometimes interfere with the conduct of the cen- 
sus. In Myanmar, the last 2014 census was marred with serious irregularities regarding the implementation of the international methodological and human rights standards. International recommendations clearly require the option for self-declaration of ethnicity and the indication of multiple ethnic affiliations (as opposed to using pre-established classifications). The Government of Myanmar listed 135 predefined official ethnic categories, comprising eight major groups and sub-groups. However, this list did not enjoy consensus among ethnic leaders. Early on in the preparations, UNFPA advised the Government to ensure that self-identification would be respected for all. Nevertheless, a few days prior to start of enumeration, the Government reneged on its commitment to allow for the self-identification of all ethnic groups, as it refused to enumerate those who would declare Rohingya as their ethnicity. As a consequence, the census did not cover certain areas of Kachin and Kayin States as well as in Northern Rakhine, where communities were not allowed to selfidentify as "Rohingya". Analysis of census information by the Department of Population, in charge of conducting the census, revealed and estimated total of over 1,200,000 not enumerated in parts of the Rakhine State, Kachin State and Kayin State. This represents 2.34 percent of the population [3].

Less tragic is the tentative to inflate the population counts of a municipality or region for financial or political reason. The census in many countries is the basis on which apportion the sharing of funds or seats at the Parliament, or even representativeness in the national Government. Thus, fraud attempts are observed in many countries, developing as well as developed, in particular when local authorities are involved in census operations. Census Commissions, established in several countries, are often problematic in that regard. Depending on their composition, their role can include logistics support but in some cases also "democratic" control of the census operations. Composed of local citizen but also political or ethnic groups representatives, they sometimes exceed their mandate, giving direct instructions to census field workers, in contradiction with the methodology, for example to enumerate persons who are not resident.

The census communication campaign can also be used by the Government to promote its achievements or policy, with the risk to reinforce the perception of the population that the census is an administrative operation conducted by the Government.

\subsection{Processing}

Governmental interference with the processing of census data is more complex to witness. However, instructions given to the census agency regarding the process of data editing can have consequences on the census results, including population counts. In BosniaHerzegovina, the three statistical agencies (Statistical office of the Federation of Bosnia-Herzegovina, Statistical office of Republika Srpska and National Agency for Statistics) did not agree on the way to determine the resident status of enumerated persons, based on their responses to several probing questions in the 2013 census form. The situation with the three statistical agencies ultimately escalated into the political and public debate, receiving broad attention in the country. After more than one year of discussion, the Director of the Agency for Statistics took the decision to implement the recommendations of the International Monitoring Operation [4], which was still contested by one of the entities statistical office, who decided to perform its own data processing and publish its own figures, which at the end revealed to be close to the official ones.

\subsection{Dissemination}

Political interference can also occur during the dissemination phase, due to the importance of census figures in the political and social context of a country. As census population counts are often used to apportion seats in the Parliament, or share public funds, they are of high importance for political leaders. In addition, ethnic or religion distribution may have consequences on the social balance of influence in a country.

As evidence of lack of independence of the census agency in the release of census results, some countries have the practice to seek formal "approval" by the President of the Republic on the census population counts, and examples exist of non-approval leading either to non-publication of the results or even possible alteration of the counts. Delay in the release of results is also a way of depreciating census results.

The results of the census 2005 of Cameroon were released only in 2010 and were disputed. Census results, especially the distribution between the Muslim North and the Christian South, have often sparked controversy in Nigeria, and the results of the 2006 census were no exception [5]. The provisional results of the 2006 census were released by the President in January 2007 and immediately criticized, both on the level of 
the total population, just above 140 million, and on the distribution of state population [6].

Kenya is an interesting case of politico-judicial interference in the census process. During tabulation of the 2009 census, it became clear to Kenyan population specialists that the population figures were higher than expected in eight counties in the North Eastern Province. ${ }^{1}$ Due to failure of the post enumeration survey in this region, the problem was unfortunately not detected earlier. During the official release of the census results in 2010, the Minister for Planning, National Development and Vision 2030 nullified the census results in these eight counties and announced a recount of the area to obtain more accurate population data. The recount was barred by the High Court after members of parliament from the area filed a case. The judge in the case decided that the actual enumerated data were the official figures and should form the basis for further analysis. This had serious consequences for the subsequent use of census data.

According to Goble [7], Turkmenistan's Government did not release the results of the 2012 Census that seems to have revealed that the actual population was far less than official claims and the ethnic composition too differed from that expected by the Government.

Data on religion of the census 2011 of India were released only in August 2015. Observers, both within and outside India, alleged that the 2011 Census data on religion were not released due to electoral considerations [8].

\subsection{Confidentiality}

Strict confidentiality safeguards are needed to protect census data from political interference. It has happened that government officials, or political parties request or exert pressures on the Statistical Office to access to individual census forms or records. In Montenegro, the Director General of the Statistical Office faced a lawsuit because she refused to grant access to census forms to a political party. Fortunately, the Court ruled in favour of the Director of the Statistical Office. However, it shows the lack of respect of statistical confidentiality that some politicians display, but also the difficulty to educate people that a population census is a strictly statistical operation, and not an administrative one.

\footnotetext{
${ }^{1}$ Lagdera, Wajir East, Mandera Central, Mandera East, Mandera West, Turkana Central, Turkana North and Turkana South.
}

\section{How to maintain the census away from political or undue government interference?}

The UN Principles and Recommendations for Population and Housing Censuses [9] highlight the importance that national statistical/census agencies maintain professionalism and demonstrate neutrality and objectivity in the presentation and interpretation of the results and are free from real or perceived political interference so that the objectivity and impartiality of the statistics is assured, because this in turn will build trust in and acceptance of the results.

The question is thus how avoid political interference in census operations. The first response is to have appropriate legislation ensuring the independence of official statistics. This is even more needed as in many countries, the National Statistical Office (NSO) or the Census Agency is part of the public administration, organised/subordinated to under the responsibility of a line minister. European Member States have to comply with the European Statistics Code of Practice, of which first principle is professional independence, meaning that the independence of the National Statistical Institutes from political and other external interference in the production, production and dissemination of statistics is enshrined in law and guaranteed for other statistical authorities. ${ }^{2}$ Statistics acts in various countries, as South Africa, include provision related to the sole responsibility of the Chief Statistician to determine, and exercise final responsibility regarding the data collection, methodology, and dissemination of statistics.

This entails that the National Statistical Office or the Census Agency should be entrusted with the full responsibility of conducting the population and housing census, including designing, conducting the operation, processing and disseminating the results. National Census Commissions, when existing, should restrict their role to support to the census, but not to decide on the content of the census questionnaire and the methodology. In North Macedonia, the Statistical Office was by law deprived of full responsibility for the census 2011. The law provided that "the Census is organized and conducted by the State Census Commission in co-operation with the State Statistical office". The Commission felt entitled to challenge the methodology proposed by the State Statistical Office, which

\footnotetext{
${ }^{2}$ European statistics Code of Practice - revised edition 2017 Available from: https://ec.europa.eu/eurostat/documents/4031688/ 8971242/KS-02-18-142-EN-N.pdf/e7f85f07-91db-4312-8118-f729 c75878c7.
} 
was in compliance with international recommendations, creating a confusing situation on the ground, leading to the cancellation of census operations after ten days.

This of course does not mean that the Statistical Office shall decide on its own on the content of the questionnaire and not organize stakeholders' consultations. In that regard, Statistical Councils composed of representatives of users, from governmental departments, the public sector, civil society organizations and the private sector, are useful institutions to ensure that the topics included in the census questionnaire, as well as other statistical operations, are fully relevant.

At local level, the need for census commissions should be carefully evaluated. Are they really needed? Logistical support can be carried out by one person responsible at local authority level to provide training facilities, storage space, and support fieldworkers in case of refusals to respond to the census. The "political" control of the enumeration, sometimes entrusted to local census commissions, is highly questionable, as it insinuates that the NSO may not be reliable to conduct the census in a neutral way, thus raising suspicion about the operation.

International organisations have also a role to play. They support censuses in many developing countries, organizing resource mobilization and providing technical assistance. This gives them the right and ability to publicly denounce misconducts and even withdraw support, but they rarely use it. Stronger donor involvement in ethics and compliance with international standards in the conduct of census operations would also help mitigate political interference in the censuses they support.

\section{Conclusions}

While promoting and supporting the population and housing census, the Government must adopt a neutral attitude, refraining from taking the lead over the operation, with the risk that the census would be seen by the population as a governmental operation. The Government should communicate on the importance of the census for the country but emphasizing the role of the NSO in designing and conducting the operation. It is also very important to clearly separate the census from other operations, such as using the census to build an administrative register, unless this is explicitly provided by the census law, or asking the enumerators to collect information for additional survey, for example on the opinion of the public on a governmental project. The publication of the census results should be the sole responsibility of the NSO or Census agency, without any "approval" from the Government, even where the population counts are authenticated in the official gazette.

Finally, the role of the media is key in a democracy. They must be informed early enough of the privacy and neutrality purpose and safeguards of the census, to ensure that enumeration and subsequent steps are conducted in accordance with these principles. Regularly communicating with the media is the best way for the NSO to ensure transparency throughout the census operation.

\section{References}

[1] Fundamental Principles of Official Statistics. Resolution adopted by the United Nations Economic and Social Council on 24 July 2013. E/RES/2013/21. New York, 2013.

[2] United Nations Handbook on the Management of Population and Housing Censuses, rev. 2. Final draft, unedited, not typeset. New York. Available from: https://unstats.un.org/unsd/publica tion/seriesF/Series_F83Rev2en.pdf.

[3] The 2014 Myanmar Population and Housing Census. The Union Report. Census report volume 2. Department of Population, Ministry of Immigration and Population, May 2015.

[4] Hoh, A-L. When counting counts' - Europeanisation of census taking in Croatia, Bosnia and Herzegovina and the Former Yugoslav Republic of Macedonia, Journal of Contemporary European Research. 2007: 13(1).

[5] Yin, S. Objections Surface over Nigerian Census Results. PRB. Accessed from: https://www.prb.org/objectionsovernigerian census/, 2007.

[6] Akinyoade, A et al. Census-taking in Nigeria: the good, the technical, and the politics of numbers. African Population Studies. 2017: 31(Supp 1).

[7] Goble P. Unpublished census provides rare and unvarnished look at turkmenistan, Eurasia Daily Monitor. 2015: 12(26).

[8] The Economist (2013). "India's Muslims Growing, and neglected." March 2.

[9] United Nations (2015). Principles and recommendations for population and housing censuses the 2020 round, rev. 3. Series M. No. 67/Rev. 3. New York. 